\title{
NOTAS SOBRE EL ARBITER ROMANO Y SU POSIBLE RELACION CON EL IUDEX
}

\author{
CANDIDA GUTIERREZ GARCIA \\ Profesora de Derecho Romano
}

Estas notas surgen dado que el hombre en el momento que se une a otros para vivir en sociedad, afluyen desacuerdos que amenazan la convivencia, la armonía y la paz, por ello busca desde un principio medios de solventarlos y establecer el orden.

Tres son los medios utilizados por el hombre para conseguirlos:

$1^{\circ}$ La via de transición, que no precisa la asistencia ajena y las partes son sus propios jueces, resolviendo las diferencias con acuerdos que ellos mismos deciden mediante cesión de derechos por ambas partes.

$2^{2}$ La vía judicial, a la que acuden las partes para someter sus debates a la autoridad pública. Medio cierto, pero sin duda el más riguroso y complicado que aparece en Roma cuando ya existe como Estado avanzado que puede permitirse la intromisión en la vida de sus ciudadanos.

$3^{\circ}$ La via de arbitraje, medio que sin presentar las ventajas de los precedentes, al menos tiene el privilegio de ser la primera en Roma a la que acuden aquellas partes que intentan sustituir la venganza privada, buscando la equidad, aún cuando en un principio se limitaron simplemente a la asistencia como testis sin intervenir directamente en la controversia, para dar una solución.

La ventaja que presenta esta vida es quizá, su sencillez y simplicidad, lo que permite una solución rápida al conflicto existente entre los individuos. Por el contrario, el juicio es siempre largo y complicado, por ello, se recurre frecuentemente a esta tercera via para evitar los inconvenientes de los otros dos.

El Estado Romano consciente de la utilidad de esta institución y de la frecuencia con que se accede a ella, a pesar de la existencia de procesos, decide no sólo admitirla como tal y que conviva con ellos, sino que la presta atenciòn y protección, dictando aquellas prescripciones, cuya violación supone la nulidad de la convención y por ello la anulación de la sentencia emitida.

Dada la implicación de esta institución en el mundo jurídico, estas notas pretenden suscitar el tema de la existencia de cierto paralelismo arbiter-iudex en lo que se refiere a su función juzgadora, aún cuando existan diferencias notables entre uno y otro en virtud de los diversos actos sobre los que deriva el nombramiento de cada uno de ellos.

El término iudex que no siempre fué empleado con indéntico significado, indicaba en un principio aquellos que podian ius dicere, siendo estos los magistrados que en virtud de su imperium ejercian funciones jurisdiccionales, regulando direc- 
tamente la controversia entre privados y estatuyendo caso por caso el derecho, denominación que más tarde se sustituyó por la de praetor y consul (1).

Cuando el proceso romano comienza a desarrollarse en dos fases, ya no será el iudex quien ius dicit sino, el que en la segunda fase despues de recoger pruebas y siempre limitado al planteamiento llevado a cabo en la primera fase por el magistrado dicte sentencia.

El magistado juntamente con las partes nombrará por sorteo un juez, de una lista previamente elaborada de ciudadanos romanos, no necesariamente sui iuris y de la que serian excluidos (2) mujeres, mudos, sordos y dementes, así como los menores de treinta años, en principio y de veinticinco a partir de Agusto, también se consideraron excluídos para el ejercicio de iudex aquellos que estuvieron ejerciendo función pública y en especial los revestidos del mismo o superior imperium del que gozaba el magistrado que presidia el juicio (3).

Este juez era susceptible de recusación por parte del demandado que no venia forzado a aceptarlo categoricamente siempre que tuviese motivo justo para hacerlo; y él a su vez podía excusarse y no aceptar el encargo de dictar sentencia, si estaba incurso en aquellas circustancias reconocidas como válidas para ello, como sería enfermedad, oficio público, necesidades familiares etc.

Cuando el juez asume esta función la relación con el árbitro se pone de manifiesto, y en las fuentes clásicas encontramos apoyo a esta tesis, debido a que usan indistintamente la palabra iudex-arbiter (4) para hacer referencia a aquel que venia investido de la potestas iudicandi.

Sin embargo a pesar de ello no podemos aceptar este paralelismo de forma y considerar como una misma figura ambas instituciones (5), aunque tampoco parece admisible aquella otra que rechaza cualquier posible relación sobre todo en época avanzada (6).

Compartimos más aquella otra tesis intermedia que considera que partiendo de una distinción originaria entre iudex-arbiter se pasará en el proceso formulario a una deferencia mínima, si bien, de las fuentes parece derivarse cierta predilección por el término arbiter al que se le reconocía mayor poder discreccional (7).

Es posible deducir también que no pueden ser catalogados de figuras contrapuestas, del hecho de que cuando el iudex por particulares circustancias precisa venir revestido de más amplios y descreccionales poderes, se le denomina arbiter y el proceso que lleva a cabo se le denomina arbitrium.

Wlassak nos informa que el nombre de árbitro no difiere en nada del de juez y que con el concurso de otras circustancias necesarias es legitimum el proceso en el que el órgano que juzga es el árbitro (8).

De igual modo podemos argüir cierta relación entre el llamado arbiter datus y el iudex datus cuando en época clásica y fuera del proceso ordinario era nombrado por el magistrado para aquella ocasión que siendo precisas medidas magis imperii quam iurisdictionis se acudía a él.

Africano justifica este nombramiento cuando existe un motivo cum controver- 
sia et computatio difficilior esset. A este árbitro se le ha venido identificando con el llamado iudex datus que aparece a partir del S-III d.C. como juez auxiliar que en el procedimiento extraordinario era funcionario delegado de un magistrado superior conociendo, de los asuntos que le competían a éste. Este árbitro, sin embargo, no decidía sobre una litis, sino que se limitaba a la investigación y valoración técnica sobre cuestiones de hecho, cuando se precisaban para preparar la sentencia, o bien para situaciones ocasionales que vendrían determinadas estrictamente (9).

Ya en época post-clásica en la cognitio-extraordinem arbiter venia a ser el iudex y en definitiva, son identificados igualmente, apareciendo como particular el caso de los árbitros elegidos por las partes despues que ante litem contestatum habian recusado al iudex datus (10).

En cuanto que ejercen su función buscando el mismo fin o resultado, como es emitir sentencia -no siendo siempre consegido- sin embargo no están sometidos al mismo grado de exigencia de responsabilidad en caso de no cumplir con esta obligación, derivándose ella de la forma en que uno y otro son nombrados.

Las partes que recurren a una u otra vía buscan la emisión de una sentencia, y es preciso por ello asegurarles que su fin será cumplido y que la cuestión que plantean será debatida y solucionada.

El magistrado obligará tanto al iudex como al arbiter a cumplir la función que han asumido como deber esencial que es.

Cuando el juez nombrado, acepta su cargo, su obligación es dar sentencia, de manera que si llegado el momento y sin causa que lo justifique no lo hace, incurrirá en responsabilidad (11). Llegando incluso en época justinianaa a alcanzar la ausencia de sentencia categoría casi delictual (12), apoyándose en el sistema de responsabilidad objetiva.

No hay acuerdo por parte de la romanística sobre si la responsabilidad del juez viene limitada al hecho de dar o no sentencia, o si por el contrario también se le exigiría al juez cuando siendo la condenatio certa, condenara a más o menos de la cantidad señalada, o que señalando una taxatio el juez no se atuviera a esa orden, debido a que las fuentes presentan párrafos que apoyan tanto una tesis como la otra (13).

Sin embargo la tesis más admitida y que comparto es aquella que considera que el juez vendría sometido a responsabilidad sólamente en el supuesto de no dar sentencia, en cambio no vendria incluida la responsabilidad por actuación inconveniente, pues aunque el juez estuviera obligado a un comportamiento correcto a lo largo de la fase apud iudicium en virtud de su juramento (14), éste sólo le vinculaba en su fuero interno eximiéndole al tiempo de cualquier reclamación que se intentará contra él.

No viene al caso cual sería la sanción con que el juez sería castigado ni si ésta evolucionó; la pretensión no es otra que establecer que el juez vendría obligado por su oficio a dictar sentencia desde el momento que asumió el cargo y no se excusó (si tenia causas suficientes) de la misma manera que venia obligado el árbitro que 
habiendo asumido su oficio no dictara sentencia, si tampoco utilizó las excusaciones que también tenia reconocidas.

Ahora bien, solo estaria obligado a dictar sentencia el arbiter ex compromiso, es decir, aquel que asumió el cargo mediante receptum, pues hemos de diferenciar a éste de aquel árbitro primitivo que actuaba como simple mediador, y cuya única función era la de actuar tratando de conciliar a las partes, escuchando sus alegaciones, asistiendo e iluminándolas con sus consejos, ésto no sería evidentemente una sentencia.

Será más tarde, y conforme el concepto de justicia se afirma como sanción esencial del Estado que interviene en la vida de sus ciudadanos, cuando el pretor puede actuar obligando al árbitro a emitir sentencia siempre y cuando éste haya accedido al cargo mediante receptum y dejará de ser observador, conciliador y testimonio para desarrollar una función más amplia y general que decide según sus propias convicciones y autoridad.

Cuando las partes de acuerdo mediante un compromiso para someter a arbitraje una controvertida relación jurídica y mediante la petición a un tercero para que actue como árbitro, éste acepta, esta actividad se convierte en arbiter ex compromisum. Es entonces, cuando el arbitraje viene elevado a verdadero instituto jurídico y el pretor comienza a intervenir para garantizar a las partes la labor jurídica juzgadora a intervenir para garantizar a las partes la labor jurídica juzgadora siendo preciso el recipere del árbitro, para que quede obligado a dictar sentencia, por lo que quedará sometido a la coercitio praetoria en caso de incumplimiento (15).

El Estado en estos casos no sólo acepta el arbitraje sino que garantiza a las partes que han elegido este medio para dirimir la controversia existente entre ellos, la posibilidad de que venga asegurada la decisión, castigando al árbitro que desobedezca el mandato del magistrado que emana en virtud de su imperium mediante multa o pignoris capio.

La jurisprudencia Romana a partir de una claúsula edictal que prevé la intervención del pretor para constreñir al árbitro a pronunciar sentencia, elabora este instituto, poniendo de manifiesto cual era el sentir de los jurisprudentes en esta institución y que nosotros hemos podido constatar a través de numerosos pasajes (16). El árbitro venia obligado a dictar sentencia salvo que estuviera exento por causas justificadas, reconociendo por ejemplo suficiente, el hecho de que se le hubiera hecho injuria, despreciándole al acudir a otro árbitro y volviendo después a él.

Por supuesto nunca vendría obligado mientras no mediara compromiso y una vez que receptum arbitrium (17); tampoco podría ser obligado cuando haya sido cancelada por acceptilatio la pena del compromiso a uno de los compromisarios (18). De la misma manera que no vendría forzado aquel árbitro que, mediando un compromiso de que actue en un determinado sentido, no tuviera libertad para ejercer la función conforme a su parecer.

De todo ello puede deducirse que salvo causas justificadas, por las que pueda ser excusado el árbitro a cumplir con su función juzgadora siempre quedaría sometido a la coercitio praetoria en caso de no hacerlo. 
Es este arbiter ex compromisso el que presenta semejanza con el iudex, sobre todo en cuanto al sometimiento de ambos a la exigencia de dictar sentencia, cuando aceptaran la función de juzgar, aún cuando el modo utilizado para exigir esta obligación era distinto. Creemos por tanto que ambas figuras presentan gran similitud funcional, aún cuando esto no comporte identidad estructural.

El árbitro tiene que atenerse a la hora de juzgar al programa acordado por las partes en el compromiso (19) secundum forman compromissi principio que marcha paralelo a aquel que surge del proceso ordinario (20).

Una vez emitida la sentencia cesa en su oficio de manera automática y no puede modificarla (21).

Comunes son también para ambos institutos los principios que regulan la validez de la sentencia, cuando siendo más de uno los jueces o árbitros precisa que estén necesariamente todos presentes y todos deben juzgar (22) siendo admitido y prevaleciendo el acuerdo mayoritario cuando existan distintos criterios (23).

Igualmente son semejantes en cuanto al contenido de la sentencia emitida por ambos de manera que pueden dictar: a) aseguramiento, nihil videri Titium debere Seio (24), b) condena o absolución cum constet Titium Seio dicetum condemno (25), c) adiudicatio (26).

Siguiendo con el contenido de la sentencia, el de ambos debe ser determinado, no siendo válida una sentencia que diga: cuantum ei debes reddes o bien, divisionis vestrae stare placet; su similitud también alcanza en cuanto al caracter pecuniario que debe tener la condena. Ahora bien, con caracter general se acepta por la doctrina, que la sentencia en los juicios ordinarios era siempre pecuniaria (27), no era así en lo que se refiere a que la sentencia arbitral hubiera de tener siempre esta naturaleza.

Otra pregunta que cabe hacerse con respecto a la posible relación entre la figura del árbiter y del iudex es que si una vez emitida la sentencia sea de manera voluntaria u obligatoria por el magistrado ¿alcanza el mismo grado de fuerza obligatoria la sentencia de uno y otro ?, es de suponer que así como hemos podido establecer cierto paralelismo en su obligación a la hora de emitir sentencia no será lo mismo una vez emitida, dada la diferencia existente entre un indicium y un arbitrium.

Por lo que respecta a la sentencia dada por el juez y a través de la evolución sufrida por el proceso Romano, vemos que si en un principio en los juicios llevados a cabo a través de las legis actiones la sentencia del juez venia simplemente a designar opinión o convicción jurídica del iudex privatus sobre la cuestión litigiosa, de manera que sólo producía efectos indirectos respecto de la satisfacción del derecho que el demandante pretendía hacer valer el juicio, más tarde cuando se llevan a cabo a través del procedimiento formulario los efectos producidos son directos sobre las partes, aún cuando la sentencia conserve el caracter que tenía anteriormente expresando también el criterio del juez como final de un proceso lógico mental.

A través de la evolución histórica, la afirmación que contiene la sentencia llega a alcanzar un valor peculiar que se concoce con el nombre de "autoridad o santidad de la cosa juzgada" (res iudicata). Llegando pues, a un momento en que la senten- 
cia pronunciada por un juez, valdrá como "verdad" entre las partes, merced a la cual éstas podrán en un futuro invocar su fallo, asumiendo la obligación de acatarlo, lo que supone que la sentencia dictada ha resuelto definitivamente la cuestión litigiosa. Ya nunca podrá plantearse un nuevo litigio que contenga idéntica materia litigiosa, aquello que conocemos como eadem res o eadem quaestio.

La sentencia emitida por el juez se hace de obligatorio cumplimiento, de manera que si el condenado no paga al demandante vencedor la suma establecida en la condena, éste, pasados treinta días podría actuar con la actio iudicati (28) y comenzaba el proceso ejecutivo.

Sin embargo, no podemos aceptar el mismo grado de obligatoriedad para el laudo arbitral, ya que éste nunca tendrá fuerza de cosa juzgada: ex compromisso... iudex sumptus rem indicatiorum non facit (29), constituye unicamente para el perdedor carga o gravamen, en cuanto que viene obligado, en caso de no acatar la sentencia del árbitro a pagar la cantidad que anteriormente habian estipulado por compromiso.

La parte ganadora por el contrario, no tiene medio alguno para exigir el cumplimiento de la condena a la parte perdedora; si el condenado opta por pagar la poenae compromissi no podrá ser compelido aún cuando el demandante prefiera que se cumpla. Tampoco tiene fuerza de cosa juzgada, pues si lo desean podrán acudir a un proceso ordinario, y presentar la misma controversia suscitada ante el árbitro. De esta forma, las partes son libres de pagar la pena o cumplir la sentencia, pena que anteriormente las partes habian acordado en el acuerdo compromisario y solo a ello podrán ser obligadas por el pretor, no pudiendo ser apelada la sentencia arbitral.

Todo ello no significa que no hubiera posibilidad de remedio a la sentencia emitida por el árbitro, pues desde los rescriptos de Caracalla (30), del siglo III d.C. se concedia frente a la actio ex stipulatu con que se reclamaba la pena que se había acordado en el compromiso, cuando la parte perdedora no acatara la sentencia, una exceptio doli en caso de que la sentencia del árbitro fuera dolosa. Esta misma solución se dió en otros rescriptos por los emperadores Diocleciano y Maximiano.

El Digesto también recoge la concesión de esta exceptio cuando el árbitro que emitió sentencia fuera enemigo manifiesto de una de las partes (31) o cuando exista venalidad o favor de los árbitros (32).

Es la época justinianea cuando ya se concede una actio in factum al actor victorioso $(\mathrm{C} 2,55,5$ de receptis: quatenus possit sententiam... excusationi mandari) y al demandado absuelto la defensa por medio de una exceptio cuando la misma controversia fuera decidida en juicio.

Queda pues, manifiestamente probada la diferencia existente entre la sentencia del iudex y la del arbiter en lo referente a su caracter obligatorio, por lo que en este aspecto no creemos posible establecer ningún lazo de relación entre ellos.

Y como en principio se anunció, a pesar de que en algunos aspectos si hemos considerado existente cierto paralelismo entre ambas instituciones en su función juzgadora, la diferencia entre la decisión de una y otra descansa sustancialmente en la forma distinta de su nombramiento, pues mientras el árbitro es elegido por las 
partes sin intervención del magistrado, que ni siquiera coopera en el nombramiento y que sólo podía compeler al árbitro reaccio, como dice en su edicto (qui arbitrium receperint ut sententian dicant (33)), al que habiendo aceptado el cargo y no estando incurso en causa de excusatio (34), será castigado con una sanción administrativa (multa o pignoris capio); el nombramiento del juez es, en cambio hecho por el magistrado junto con las partes litigantes, acto magistral que recibe el nombre de iussus iuducandi y que será la base de la potestas iuducandi del iudex frente al del árbiter en su acto de aceptación o receptum arbitri.

\section{NOTAS}

(1) VARRO, De lengua latina 6, 88; LIV,3,55; CICERON De Leg. 3,3,81 hacen alusión a estos.

(2) ULP 13 ad, ed D 5,1,12,12.

(3) PAUL 13 Sab D 5,1,58.

(4) CICERON de off 3, 16,66.

(5) WLASSAK, Der Röm Precessgesetze vol II, p. 287 y ss.

(6) KELLER-WACH Der Röm Civilprozess 6ª el Leipzig 1883, p. 33 y ss.

(7) BONIFACIO Arbitrio e Arbitratore (Diritto Romano) en Nov Dig p. 925 y ss.

(8) WLASSAK, op cit p. 43 y ss.

(9) Ej. arbiter de rationibus reddentis, en caso de libertad fideicomisaria condicionada a la rendición de cuentas (Marc. 2 inst. D 40,1,5,1); arbiter de alimentis patroni cuando se estima que un patrono carece de medios de subsistencia y el liberto tenga de sobra (Ulp. 2 de off const D $25,3,5,25$ ) arbiter cuius interventu tribuantur merces peculiares (Ulp. 11, ed D 4,4,7,1) etc.

(10) $1, \mathrm{C}$ de iud 3,1 a 531 .

(11) D 5,1,74. 42. 1,55.

(12) CREMADES Y PARICIO La responsabilidad del juez en el Derecho Romano clásico en "Estudios en homenaje al profesor D'ORS" 1989 p. 180.

(13) GAYO 4,52 recoge la responsabilidad de un juez que condena a más o menos de la cantidad señalada. ULPIANO 51 ad sab D 4,2,1,55 señala por el contrario que un juez que condene a más o menos no puede alterar su sentencia, pues male seu bene officio functus est de forma que una vez emitida la sentencia, lo haga bien o mal, el juez ha cumplido con su deber.

(14) LUZZATO Procedura civile romana II, 1948 p. 229.

(15) LENEL, Das Edictum Perpetuum Leipzig 1927 p. 13 a 131.

(16) D 4,8 recoge los casos de responsabilidad asumida y dice" qui arbitrium receperit sententiam dicant.

(17) D 4,8,13. 2: Recepisse autem arbitrium videtur, ut Pedius lib nono dicit, qui iudicis partes suscepit finenque se sua sententia controversiis impositorum pollicetur.

(18) D 4,8,13.

(19) D 4,8,32,15 y $16,17,21$.

(20) GUARNIERI BIDR XXXIII 1923.

(21) D 4,8,19,2 ...ceterum si condemnavit vel absolvit, dum arbiter esse disient, mutare sententiam non posse.

(22) D 42,1,37: Tunc enim universi iudices iudicare, iudicavit ratum est y D 4,8,27,33.

(23) D 4,8,18: ...quia id demum quod maior pars omnium iudicavit ratum est y $\mathrm{D} 42,1,39$. 
(24) D 4,8,21,1.

(25) D 49,8,1 y D 4,8,19,2.

(26) D 4,8,21,3.

(27)PARICIO dice, en Notas sobre la sentencia del arbiter (RIDA XXXI) que "incluso en aquellas acciones que propiamente no iban dirigidas al pago de una cantidad y también en aquellos casos que se precisaba el restituere o reddere oexhibere aunque quedaba supeditada a la no restitución, devolución o exhibición de la cosa".

(28) La actio iudicati es una de las acciones quae infitiando in duplum crescunt.

(29) PAUL sent 5,5 a1.

(30) VOCI la responsabilitá del debitore da stipulatio poenae en Studi Volterra II, 1971 p. 334 y ss.

(31) D 4,8,32,14: Cum quidam arbiter ex alis causis inimicus manifeste apparcuisset.

(32) C 1,2,55,3: si sordes vel evidens gratia eorum qui arbitrati sunt intercessit.

(33) LENEL edic prep Leipzig 1956, $3^{2}$ ed p. 130.

(34) D $4,8,11$ y 15,16 . 